\title{
Prevalence of Two Monogenean Parasites on Different Length Groups of Crucian carp (Carassius carassius Linneus, 1758)
}

\author{
Mustafa KOYUN ${ }^{1}$, Faik Naci ALTUNEL ${ }^{2}$ \\ ${ }^{1}$ Bingol University, Science and Art Faculty, Department of Biology-Zoology, 12000 Bingol, Turkey; mustafakoyun16@yahoo.com \\ ${ }^{2}$ Uludag University, Science and Art Faculty, Department of Biology-Zoology, 16000 Bursa, Turkey; altunel@uludag.edu.tr
}

\begin{abstract}
Dactylogyrus anchoratus Dujardin, 1857 and Gyrodactylus katharineri Malmberg, 1964 were identified on crucian carp, Carassius carassius L., 1758 in the present study, which was carried out between February 1999 and January 2000. A total of 117 fish specimens were examined. The infestation prevalence and mean intensity levels for $G$. katharineri was $37.61 \%$, respectivly $27.75 \pm 2.203$ and for D. anchoratus was $24.78 \%, 4.69 \pm 1.730$ per fish, respectively. The infestation prevalence and mean intensity levels were higher during spring and sumer, for the both parasites. No statistically significant preference for either sex of the fish was determined. In this study, we examined a total of 117 fish, out of which 44 (38\%) were infested by 1221 G. katharineri, and $29(25 \%)$ infested by a total of 136 D. anchoratus.
\end{abstract}

Keywords: Enne Dam Lake, Carassius carassius, Dactylogyrus anchoratus, Gyrodactylus katharineri

\section{Introduction}

The importance of fish parasites is directly related to the importance of the fish that they affect (Hoffman, 1967). Metazoan parasites, especially trematodes, can cause gill infestations and inhibite oxygen exchange across gill lamella (Mitchum, 1995). Considering these aspects, fish parasites under favorable conditions, cause economic loss by affecting the health of fishes and causing high mortality (Tripathi, 1959).

Monogenean parasites are still widespread in freshwater wildlife, on farm fishes and marine habitats. The genus Gyrodactylus is represented by a great variety of fish parasites, inhabiting both freshwater and sea water environments (Bykhovskaya-Pavlovskaya et al., 1962; Harris, 1985). Gyrodactylus members are viviparous, most mature specimens exhibit a well-formed embryo, complete with a full complement of attaching armament, within the uterus. It is often possible to observe a smaller embryo within the uterus of the first embryo and more rarely a third within the uterus of the second one (Price, 1967). Gyrodactylus are seen especially in teleost fish, frog larvae and adult amphibians, while they infect and live ectoparasitically on the skin, fins and gills of fish. The gill Monogeneans, due to their microscopic size and technical difficulties, were uncounted in their collection and study, and remained little known until the twentieth century. Monogenetic trematodes of freshwater fishes have been studied by Gussev (1967) and Kulkarni (1969). The majority of Dactylogyrids have strictly hosts, as they appear as specific parasites (Jalali, 1992).
The first relevant study about this subject has been done by Nordmann in 1832 on Gyrodactylus elegans, after which several studies have been carried on all over the world. High infestation rates of Gyrodactylus species on natural population have also been studied by several authors (Hanzelova and Zitnan, 1964; Jansen and Bakke, 1957; Kirby, 1981; Mo, 1957; Rawson and Rogers, 1964).

In this investigation, G. katharineri and $D$. anchoratus in crucian carp from Enne Dam Lake (Kütahya) were studied during the year of 1999-2000. Here we report the ectoparasitic infestations of $G$. katharineri as a monogenetic parasite as being noticed for the first time in Turkey.

\section{Materials and methods}

A total of 117 fishes collected on a monthly basis were examined with a stereo microscope to determine their ectoparasite community. The fishes were separated according to their sex and were measured for the total length. The first microscopic examinations were done for observing ectoparasites and identifying any cysts, ulceration and scars. Skin, gills and fins were examined and the parasites were counted separately for each body part of the host fish. Then the gill filaments were dissected out of the branchial cavity and placed in a petridish containing saline solution $(0.75 \% \mathrm{NaCl})$. Parasites were collected and preserved, and identification was performed according to the characteristics described by Malmberg (1962) and Harris (1982). All of the collected parasites were kept in tap water, fixed in $10 \%$ formaldehyde and transferred to 5\% glycerol in 70\% 
18

ethanol after 1 week. In addition, at least 10 specimens of Gyrodactylus and Dactylogyrus were placed on glass microscope slides with a drop of $1 / 4000$ formalin while the cover slip was placed over the parasite. They were fixed in glycerin alcohol ( 90 parts of $70 \%$ ethyl alcohol and 10 parts of glycerol), stained in Borax carmine and finally mounted in glycerin jelly. Descriptive terminology fallows, with length and width hard parts (Malmberg, 1970).

All measurements are given in millimeters. The terms infestation prevalence (\%) and mean intensity are used in accordance with the definitions established. The prevalence (\%) was calculated as the percentage of the total number of fishes infested out of the total number of fishes examined (Bush, 1997). The mean intensity was calculated as the average number of parasites on the total number of infected fishes.

\section{Results}

Out of the 117 fish specimens examined, 44 were infested with $G$. katharineri, resulting a prevalence of $37.61 \%$ and mean intensity levels $27.75 \pm 2.203$., while 29 fishes were infested with $D$. anchoratus, and its prevalence was $24.78 \%$ and mean intensity levels $4.69 \pm 1.730$ per infested fish (Tab. 1).

During this study, the highest infections with $G$. katharineri and $D$. anchoratus were recorded on 146-184 mm lenghts fishes (50\%, 34.62\%). Totally 215 specimens for $G$. katharineri, and 136 specimens for $D$. anchoratus were recorded in this group. Mean intensity of $G$. katharineri was $69.22 \pm 20.83$ in $138-142 \mathrm{~mm}$, and for $D$. anchoratus was $6.12 \pm 2.232$ in $102-124 \mathrm{~mm}$ group.

The prevalence and intensity of parasitic infestation in different length groups of female and male crucian carps are given in Tab. 2. These parasite species were found on all sizes of the host fishes. The parasites attained the maximum level on the largest fish specimens (146-184). In addition, total parts and haptor of the recorded parasites were photographed (Fig. 1 and Fig. 2).

\section{Discussion}

Out of 117 fishes, 60 were found infested by two nonnative $C$. carassius parasites. The prevalence of ectoparasite

Tab. 1. Infestation prevalence (\%) and mean intensity levels of $G$. katharineri and D. anchoratus determined from the crucian carp (Carassius carassius L.)

\begin{tabular}{|c|c|c|c|c|c|c|c|c|c|c|}
\hline \multirow[b]{2}{*}{ 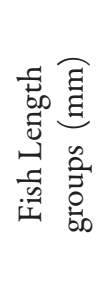 } & \multicolumn{5}{|c|}{ G. katharineri } & \multicolumn{5}{|c|}{ D. anchoratus } \\
\hline & 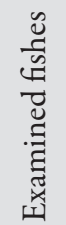 & 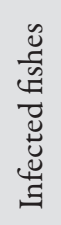 & 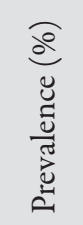 & 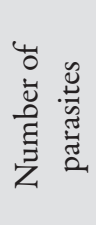 & 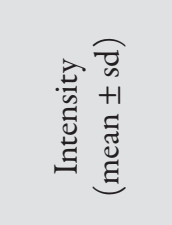 & 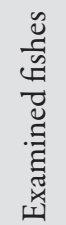 & 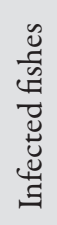 & 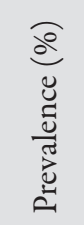 & 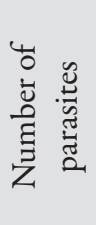 & 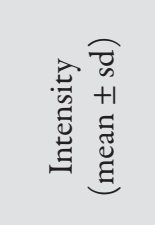 \\
\hline $102-124$ & 28 & 11 & 30.28 & 197 & $17.90 \pm 2.587$ & 28 & 8 & 28.57 & 49 & $6.12 \pm 2.232$ \\
\hline $124-138$ & 18 & 5 & 27.77 & 63 & $12.60 \pm 2.074$ & 18 & 4 & 22.22 & 9 & $2.25 \pm 0.957$ \\
\hline $138-142$ & 23 & 9 & 39.13 & 623 & $69.22 \pm 20.83$ & 23 & 3 & 13.04 & 17 & $5.66 \pm 1.528$ \\
\hline $142-146$ & 22 & 6 & 27.27 & 123 & $20.50 \pm 5.24$ & 22 & 5 & 22.72 & 19 & $3.80 \pm 1.483$ \\
\hline $146-184$ & 26 & 13 & 50.00 & 215 & $16.53 \pm 3.126$ & 26 & 9 & 34.62 & 42 & $4.66 \pm 1.803$ \\
\hline Total & 117 & 44 & 37.61 & 1221 & $27.75 \pm 2.203$ & 117 & 29 & 24.78 & 136 & $4.69 \pm 1.730$ \\
\hline
\end{tabular}

Tab. 2. Infestation prevalence (\%) and mean intensity levels of $G$. katharineri and $D$. anchoratus determined from the different length groups of female and male crucian carp

\begin{tabular}{|c|c|c|c|c|c|c|c|c|c|c|}
\hline \multirow[b]{3}{*}{ 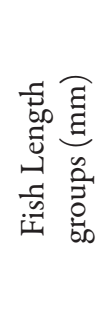 } & \multicolumn{10}{|c|}{ (C. carassius) male and female } \\
\hline & \multicolumn{5}{|c|}{ G. katharineri } & \multicolumn{5}{|c|}{ D. anchoratus } \\
\hline & 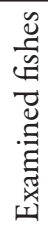 & 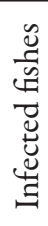 & 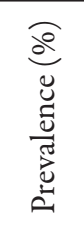 & 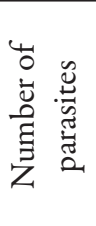 & 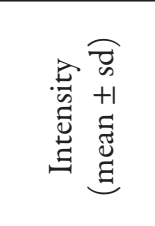 & 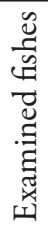 & 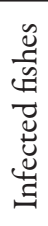 & 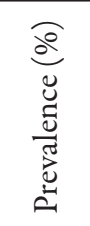 & 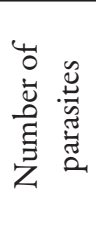 & 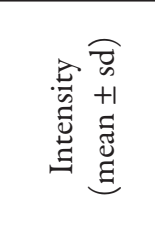 \\
\hline $102-124$ & 21 & 14 & 66.66 & 261 & $18.64 \pm 4.86$ & 7 & 5 & 71.42 & 97 & $19.40 \pm 2.61$ \\
\hline $124-138$ & 12 & 6 & 50.00 & 115 & $19.16 \pm 3.76$ & 6 & 3 & 50.00 & 58 & $19.33 \pm 1.53$ \\
\hline $138-142$ & 15 & 7 & 46.67 & 133 & $19.00 \pm 3.61$ & 8 & 5 & 62.50 & 93 & $18.60 \pm 2.07$ \\
\hline $142-146$ & 15 & 8 & 53.33 & 138 & $17.25 \pm 1.83$ & 7 & 3 & 42.86 & 52 & $17.33 \pm 2.52$ \\
\hline $146-184$ & 16 & 14 & 87.50 & 260 & $18.57 \pm 2.76$ & 10 & 8 & 80.00 & 150 & $18.75 \pm 2.96$ \\
\hline Total & 79 & 49 & 62.02 & 907 & $18.51 \pm 2.71$ & 38 & 24 & 63.15 & 450 & $18.75 \pm 2.94$ \\
\hline
\end{tabular}




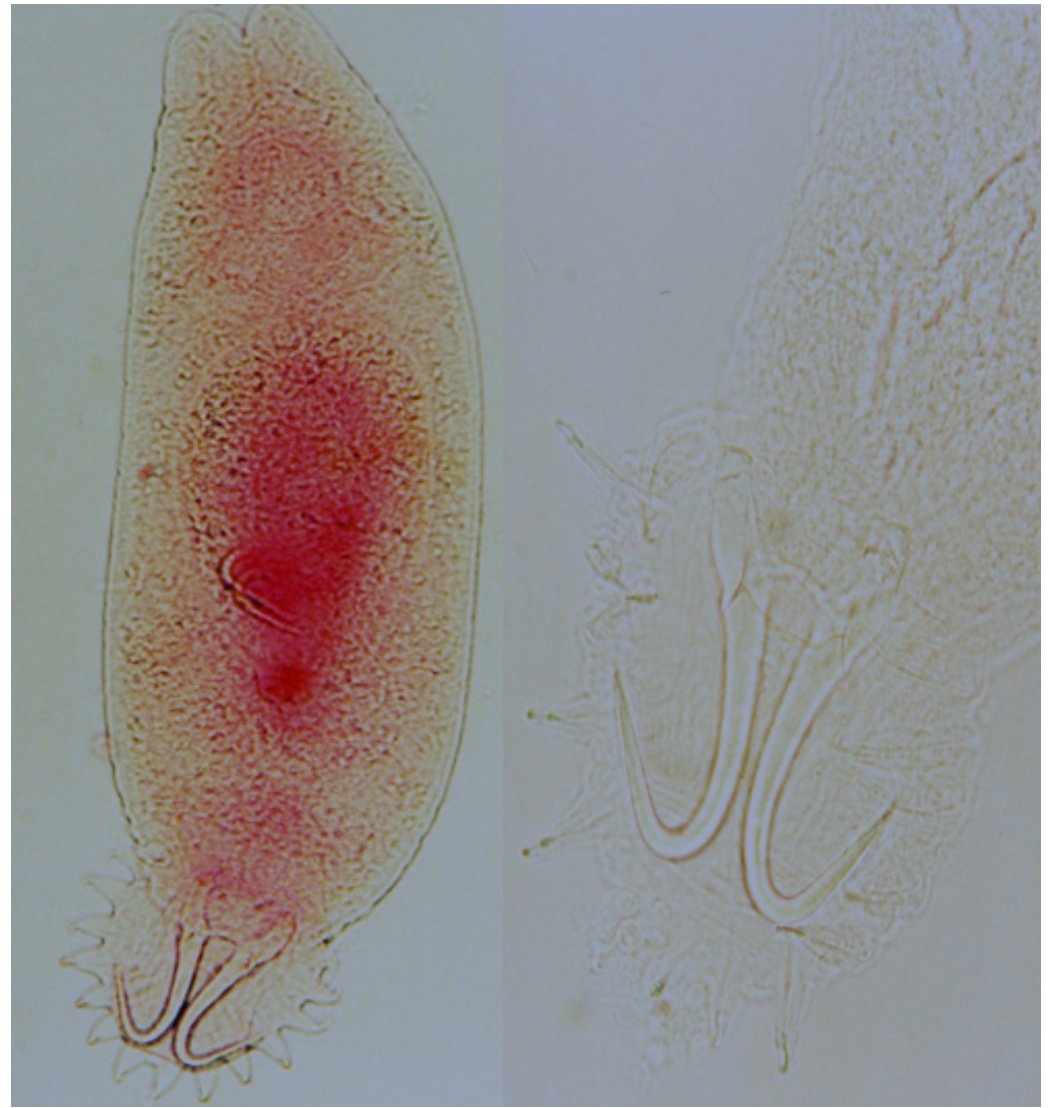

Fig. 1. G. katharineri total view and haptor part (original)

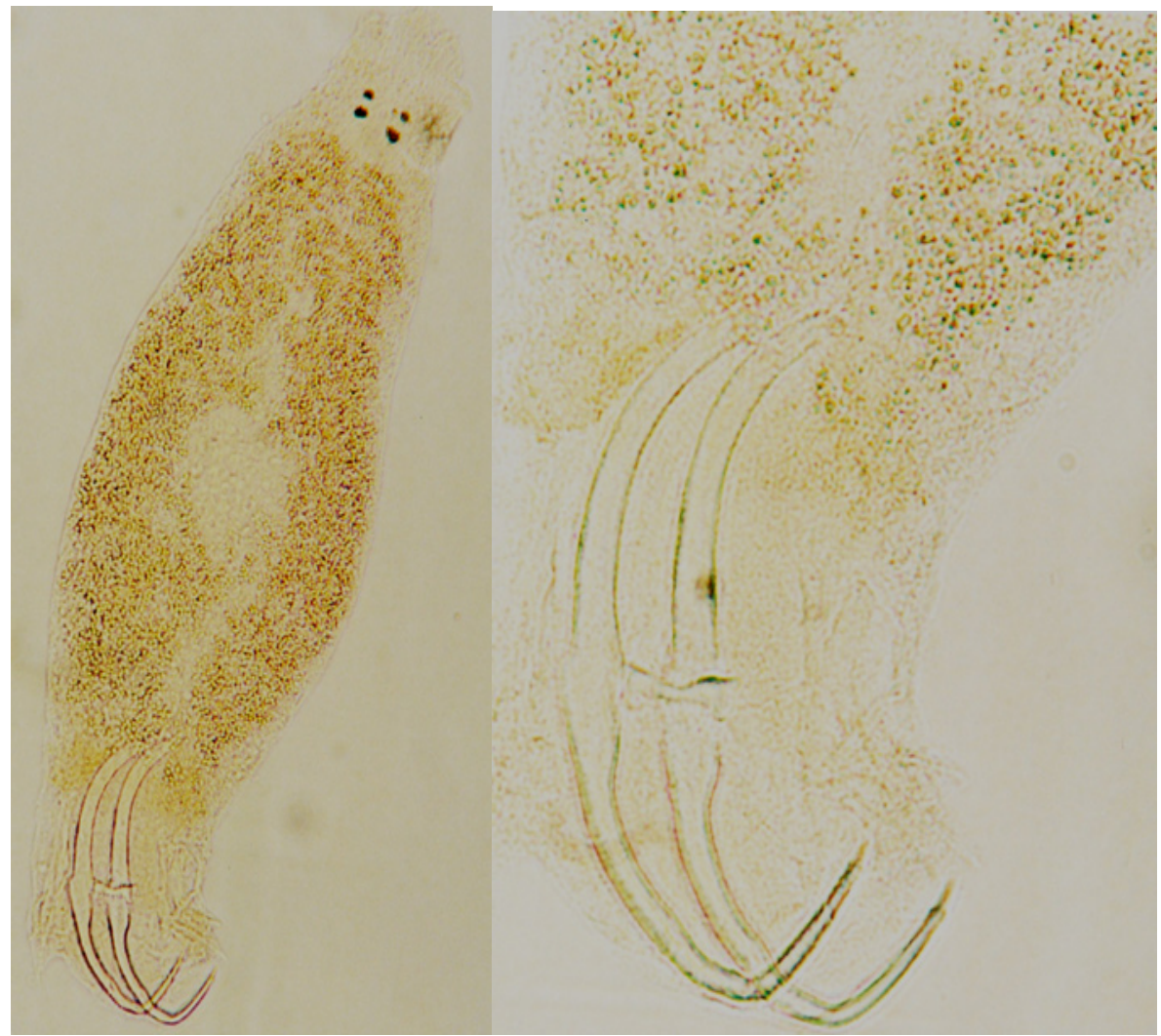

Fig. 2. D. anchoratus total view and haptor (original) 
20

infestation in these fishes was $62.39 \%$. The prevalence of. G. katharineri was $37.61 \%$ and that of $D$. anchoratus was only $24.78 \%$. The intensity of infestation was 27.25 and $4.69 \%$ in $G$. katharineri and $D$. anchoratus respectively (Tab. 1). On female fish the infestation intensity was slightly higher (18.75\%) than on male fishes $(18.51 \%)$. The prevalence of $G$. katharineri was found highest (50\%) in 146-184 mm length group while the highest intensity (69.22 and 20.50) was found in 138-142 mm and 142-146 $\mathrm{mm}$ groups, respectively. Similarly, the prevalence and intensity of $D$. anchoratus were found highest $34.62 \%$ and $4.66)$ in the length group of $146-184 \mathrm{~mm}$. The effect of fish length on parasite infestation has been observed during the study period (Tab. 1). In different length groups of C. carassius, it was observed that the fishes of the $1^{\text {st }}$ and $2^{\text {nd }}$ intermediate length groups were more infested than the smaller and larger group of fishes.

Bashirullah (1973) reported that the degree of parasitism was obviously related to the age of the host fishes. As shown in Tab. 2, the prevalence and intensity of parasites in males and females of $C$. carassius in different length groups also varied. The prevalence of parasite infestation in male fish $(63.15 \%)$ was higher than for the female fishes $(62.02 \%)$. The intensity of infection was nearly equal $(18.75 \%)$ in male and in female $(18.51 \%)$.

In the smallest length group (102-124 mm), the prevalence of infected male (71.42\%) was higher than on female $(66.66 \%)$. In the $1^{\text {st }}$ intermediate length group (138-142 $\mathrm{mm})$, the prevalence of male $(62.50 \%)$ was higher than that of female (46.67\%), but the intensity was higher on female fishes. In the $2^{\text {nd }}$ intermediate length group (142$146 \mathrm{~mm}$ ) the highest prevalence of infestation was shown by female fish $(53.33 \%)$. In the highest length group (146$184 \mathrm{~mm})$ the prevalence of infestation was higher in female $(87.50 \%)$ than in male $(80 \%)$. The intensity was also higher in male $(18.75 \%)$ than in female $(18.57 \%)$.

Out of the two non-native types of parasites, Gyrodactylus showed a higher prevalence of infestation. The prevalence and intensity of Gyrodactylus were $37.61 \%$ and $27.75 \%$ respectively. Dactylogyrus showed therefore a lower prevalence of infection. The prevalence and intensity of Dactylogyrus were $24.78 \%$ and $4.69 \%$ respectively.

The majority of parasites showed higher intensity in the case of male hosts (18.75\%). It was observed that the infestation of $G$. katharineri started from very early stages of fishes $(102-124 \mathrm{~mm})$. The prevalence was highest $(50 \%)$ in the second intermediate length group and lowest $(27.27 \%)$ in the fifth intermediate length group. The intensity was highest $(69.22)$ in $3^{\text {rd }}$ intermediate length group and lowest (12.6) in the smallest length group.

In the case of $D$. anchoratus, 136 parasites infested 29 fishes, grouped in five length intervals. The prevalence was highest $(34.62 \%)$ in the $2^{\text {nd }}$ largest length group and lowest (13.04\%) in the $3^{\text {rd }}$ intermediate length group. The highest intensity (6.12) was in the largest length group and the lowest one $(2.25)$ in the $5^{\text {th }}$ intermediate length group (Tab. 1). Among the gill inhabiting parasites, $G$. katharineri has been reported for the first time by Malmberg (1962). Harris (1985) reported about Gyrodactylus species in different places of the fish body and that they are widespread throughout freshwater and marine habitats.

The present work states for the first time that G. katharineri parasites were noticed on $C$. carassius fishes in Turkey. Monogenetic trematodes have been studied by Leuckart (1827), Mamaev (1981) and Hargis (1955). As hosts, the female fishes were more infected than the male ones. Thomas (1964), Bibbly (1972), Watson and Dick (1980) concluded that due to lower physiological resistance, the female sex of the fishes is responsible for a higher infestation rather than ecological conditions. The present study recorded a significant relationship between the host length and the intensity of parasites in C. carassius.

The study revealed that the fishes of the $2^{\text {nd }}$ intermediate (146-184 mm) and the ones of 102-124 mm length were more heavily infested than the smallest and the $1^{\text {st }}$ intermediate length groups. These results are in accordance with those of Stromberg and Crites (1975), who reported that the prevalence and intensity of infestation generally increased with the host's size, up to a certain point and then declined.

\section{Conclusions}

The aim of this study was to determine the distribution of parasites, according to the fish size and gender. As seen in Tab. 1 and Tab. 2, showing differences in parasite prevalence, the density was close to each other in all cases. Similar studies confirm the data recorded in Turkey (Altunel, 1981; Kartal and Ozturk, 2009; Ozturk, 2000; Ozer et al., 2004).

\section{References}

Altunel FN (1981). Research of the Plathelmint Parasites in Mullet Fish in (Mugil cephalus, Liza aurata, L. saliens, L. ramada, Chelon labrosus, Oedalechilus labeo) Turkey's Aegean coast. Veterinary and Livestock Research Group of Tubitak, Project work. No: VHAG 401, Ankara.

Bashirullah AKM (1973). A brief survey of the helminth fauna of certain marine and freshwater fishes of Bangladesh. Bangladesh J Zool 1(1):63-81.

Bibbly MC (1972). Population biology of the helminth parasites of Phoxinus phoxinus. The minnow, in a Cardiganshire lake. J Fish Biol 4:389-393.

Bush AO, Lafferty KD, Lotz JM, Shostak AW (1997). Parasitology meets ecology on its own terms: Margolis et al. Revisited, J Parasitol 83:575-583.

Bykhovskaya-Pavlovskaya IE, Gussev AV, Dubinina MN, Izyumova NA, Smirova TS, Sokolovskaya IL, Shtein GA, Shulman SS, Epshtein VH (1962). Key to parasites freshwater fishes of the USSR. Izdatel'stvo Akademi Nauk 
SSSR, Moskova, Leningrad (in Russian).

Gussev AV (1967). The results and perspectives in the study of freshwater monogeneans of USSR. Zool Journal 46(11):1630-1640 (in Russian with English Summary).

Hanzelova V, Zitnan R (1964). The seasonal dynamics of the invasion cycle of $G$. katharineri Malmberg (Monogenea). Helminthologia 19:257-265.

Hargis WJ (1955). Monogenetic trematodes of Gulf of Mexico fishes. Part VI. The super family Polystomatoidea Price, 1936 and Diclidophoroidea Price, 1936, Trans Amer Micro Soc 74:361-377.

Harris PD (1982). Studies on the Gyrodactylidae (Monogenea). $\mathrm{PhD}$ thesis, University of London.

Harris PD (1985). Observations on the development of the male reproductive system in Gyrodactylus gasterostei Glaser, 1974. Parasitology 91:519-529.

Hoffman GL (1967). Parasites of North American freshwater fishes. Univ. of California Press, Bekeley.

Jalali B (1992). Description of Dogielius molnarin sp. (Monogenea: Dactylogyrdae) from the gills of an Iranian freshwater fish, Cyprinion macrostomum (Heckel). Acta veterineria Hung 40(4):239-242.

Jansen PA, Bakke TA (1957). Temperature dependent reproduction and survival of Gyrodactylus salaris Malmberg, (Platyhelminthes) Monogenea on Atlantic salmon (Salmo salar L.). Parasitology 102:105-112.

LeuckartFS (1827). Versuch einer naturgemässen eintheilungder helminthen, p. 1-88. In: Neue Akademische Buchhandlung von Karl Gross. Heidelberg, Leipzig, Germany.

Kartal K, Ozturk MO (2009). Investigations of Ectoparasite Fauna of Some Fish Species (Cyprinus carpio Linnaeus, 1758; Cobitis simplicispinna Hanko, 1924) from Lake Akşehir (Konya) Turkish Journal of Parazitol 33(1):101-106.

Kirby JM (1981). Seasonal occurrence of the ectoparasite Gyrodactylus atratuli on spotfin shiners. Trans Am Fish Soc 110:462-464.

Kulkarni T (1969). Studies on the monogenetic trematodes of fishes found in Hyderabad, Andra Padesh (India). Part 1. Riv Parasitol 30(2):73-90.
Malmberg G (1962). Taxonomical and ecological problems in Gyrodactylus (Trematoda, Monogenea) Zoological Institute, University of Stockholm, Sweden.

Malmberg G (1970). The excretory systems and the marginal hooks as a basis for the systematics of Gyrodactylus (Trematoda, Monogenea). Ark Zool 23:1-235.

Mamaev YUL (1981) Some new monogenean species and genera of the family Mazocraeidae. Helminthologica 18:169-187.

Mitchum DL (1995). Parasites of Fishes in Wyoming. Wyoming Game and Fish Dept., Wyoming.

Mo TA (1957). Seasonal variations in the prevalence and infestation intensity of $G$. salaris Malmberg, (Monogenea: Gyrodactylidae) on Atlantic Salmon parr, Salmo salar L. in the River Batnfjordselva. Norw J Fish Biol 42:697-707.

Ozturk MO (2000). Helminth fauna of Manyas bird lake fish. Ph.D thesis. U. U. Institute of Science, Department of Biology, Bursa.

Ozer A, Ozturk T, Ozturk MO (2004). Prevalence and Intensity of Gyrodactylus arcuatus Bychowsky, 1933 (Monogenea) Infestations on the Three-Spined Stickleback, Gasterosteus aculeatus L., 1758. Turk J Vet Anim Sci 28:807-812.

Price CE (1967). The freshwater monogenetic trematodes of Africa. Rew Zool Bot Afr LXXVI:3-4.

Rawson MV, Rogers WA (1964). Seasonal abundance of Gyrodactylus macrochiri Hoffmann and Putz, on bluegill and largemouth bass. J Wildl Dis 9:174-177.

Stromberg PC, Crites JL (1975). An analysis of the changes in the prevalence of $C$. ocycephahus in western lake. Jour Dci 751:117-124.

Thomas JD (1964). A comparison between the helminth burdens of male and female brown trout, Salmo trutta L. from a natural population in the river Teify. West Wales Parasitol 4:263-272.

Tripathi YR (1959). Monogenetic trematodes from fishes of India. Indian J Helminthol 9(1-2):1-149.

Watson RA, Dick TA (1980). Metazoan parasites of pike Esox lucius from southern Indian lake, Manitoba. Canada. J Fish Biol 17:252-262. 